\title{
IDENTIFICATION OF A METHODOLOGY TO ESTIMATE VEHICLE EMISSIONS IN SRI LANKA
}

\author{
J M S J Bandara' and N J G J Bandara ${ }^{2}$ \\ 1University of Moratuwa \\ 2University of Sri Jayewardenepura
}

\begin{abstract}
Estimates available to date in Sri Lanka show that the transport sector is responsible for majority share of the gaseous emissions to the environment when compared to any other sector such as industry. agriculture. and fisheries. This pattern is applicable to most of the countries all over the world. Many countries have taken steps towards controlling vehicle cmissions and Sri Lanka is scriously considering actions to control vehicle cmissions.
\end{abstract}

In order to have an effective control system it is necessary to identify different emissions and the significance of their eflects to the convironment and health. The main pollutant gases emitted from vehicles are Carbon dioxide. Nitrogen oxides, Carbon monoxide, volatile organic compounds and Sulfur oxides. As the effects and the significince could change from place to place and also depend on different concentration levels, it is very important to estimate the emission to the environment to some accuracy.

Numbers of different techniques have been used for the emission estimates. They include very approximate methods such ats fue sales to very sophisticated technigues such as remote sensing measurements and simulation models. Whereas the simple techniques require little base line data and equipments, more sophisticatted techniques would require considerable amount of base line information and equipment

The technique employed today in Sri Lanka is only a simple method hased on emission factors. This yuantification is done laking into accoun the emission factors roughly estimated for each type of vehicle and on the total number of vehicks in the entire country. Only this can be used because of the difficulty laced in estimating the emission factors at a particular time and because of the lack of use of basic data on vehicle transportation. From this technique the automobile emissions at a particular location at any given time cannol be estimated.

However automobile emissions will vary according to the age of the vehicle, its travel speed and location. In order to incorporate these factors into the main estimation basic data on the number of vehicles at each place and their travel specds have to be known.

The objective of this research is 10 identify a suitable methodology incorporating the available data on traffic movement patterns to estimate vehicle emissions in Sri Lanka and to identify required development in the future to improve the estimating and monitoring procedure. In this paper eflects of different types of emissions, their signilicance and relevance to the local conditions are discussed. Methodologies available to measure and estimate selected types of emissions are also discussed. Based on this knowledge and depending on the technology and information available locally, a suitable procedure to estimate vehicle emissions that will be uselul for any future control and monitoring is identilied.

Procesedings of the Fourth Ammal Forestry and Emiromment Symposium 1998 of the Department of Forestry and Emironmental Science. University of Sri Jayewardenepura, Sri Lanka 